\title{
Internet Assigned Numbers Authority
}

National Cancer Institute

\section{Source}

National Cancer Institute. Internet Assigned Numbers Authority. NCI Thesaurus. Code C80274.

The entity that oversees global IP address allocation, root zone management for the Domain Name System (DNS), media types, and other Internet protocol assignments. It is operated by the Internet Corporation for Assigned Names and Numbers (ICANN). 